\title{
Modeling of the deoxidization process on submerged arc weld metals
}

\author{
Hirohisa Tanabe $\cdot$ Hiroyuki Hirata $\cdot$ Kazuhiro Ogawa $\cdot$ \\ Masahiko Hamada
}

Received: 18 October 2012 / Accepted: 23 August 2013 /Published online: 8 September 2013

(C) The Author(s) 2013. This article is published with open access at Springerlink.com

\begin{abstract}
Fixed welding tests were performed to investigate deoxidization during submerged arc welding and to develop a model for it. For all the chemical compositions of the fluxes used, the oxygen content of the weld metal decreased with increasing arcing time in the initial stage of welding. The oxygen content of the weld metal eventually became constant; this is assumed to be a quasi-equilibrium state. Both the rate of reduction of the weld metal oxygen content and the oxygen content of the quasi-equilibrium condition depend on the chemical composition of flux. The weld metal oxygen content in the quasi-equilibrium condition can be estimated thermodynamically. In addition, the rate of reduction of the weld metal oxygen content satisfies the following equation.
\end{abstract}

$[O]=\exp \left[-k \cdot t+\ln \left([\mathrm{O}]_{\mathrm{i}}-[\mathrm{O}]_{\mathrm{e}}\right)\right]+[\mathrm{O}]_{e}$

Where $[\mathrm{O}]$ is the weld metal oxygen content at arcing time $t,[\mathrm{O}]_{\mathrm{e}}$ is the oxygen content in the quasi-equilibrium state, $[\mathrm{O}]_{\mathrm{i}}$ is the oxygen content immediately after starting welding, and $t$ is the arcing time. We found that the coefficient $k$ decreases with increasing viscosity of the molten slag, which mainly depends on the chemical composition of the flux. Based on these results, we found that deoxidization in weld metal during submerged arc welding can be predicted by estimating $[\mathrm{O}]_{\mathrm{e}}$ and $k$ and briefly determining $[\mathrm{O}]_{\mathrm{i}}$.

Keywords Oxygen $\cdot$ Ferrous metals $\cdot$ Welding $\cdot$ Slag metal reactions $\cdot$ Viscosity

Doc. IIW-2416, recommended for publication by Commission IX "Behaviour of Metals Subjected to Welding".

H. Tanabe $(\bowtie) \cdot$ H. Hirata $\cdot$ K. Ogawa $\cdot$ M. Hamada Nippon Steel \& Sumitomo Metal Corporation, Tokyo, Japan e-mail: tanabe.sn9.hirohisa@jp.nssmc.com

\section{Introduction}

In recent years, high-strength pipelines are increasingly being used to reduce the material cost of pipelines by making their walls thinner and to reduce the transport costs of natural gas by transporting it at a higher pressure. Since most pipelines are installed in cold regions, the weld metal requires lowtemperature toughness. Reducing the oxygen content of weld metal improves its toughness because increasing the Charpy upper shelf energy reduces the volume of inclusions, which act as origination for ductile fracture [1]. The oxygen content of submerged arc weld metal is conventionally predicted from the flux basicity [2-4]. For example, Eagar investigated the relationship between the flux composition and the weld metal oxygen content and derived an equation to estimate the weld metal oxygen content from the flux basicity [2]. However, the oxygen content varies greatly at low basicities, while the dependence between the oxygen content and the flux basicity is unclear at high basicities.

The present study investigates the deoxidization process during submerged arc welding and proposes a model for determining the weld metal oxygen content. This study investigates how the weld metal oxygen content varies with the arcing time by fixed welding (in which the welding torch is fixed), demonstrates the correlation between the flux property of slag viscosity and weld metal oxygen content, and proposes a model for determining the weld metal oxygen content using thermodynamic and kinetic calculations.

\section{Experimental}

\subsection{Fixed welding test}

To investigate how the weld metal oxygen content varies with the arcing time, fixed welding (in which the welding torch is 
Table 1 Chemical compositions of materials used (mass \%)

\begin{tabular}{lllllll}
\hline & C & Si & Mn & P & S & Others \\
\hline Base metal & 0.21 & 0.22 & 0.72 & 0.013 & 0.010 & Ni, Cr, Mo \\
Welding wire & 0.06 & 0.21 & 1.95 & 0.007 & 0.006 & \\
\hline
\end{tabular}

fixed) was conducted. Commercial carbon steel-base metal was worked to a thickness of 25 or $60 \mathrm{~mm}$, a width of $150 \mathrm{~mm}$, and a length of $150 \mathrm{~mm}$. The welding wire was $4 \mathrm{~mm}$ in diameter. Table 1 lists the chemical compositions of the base metal and welding wire and Table 2 shows that of the flux used in the fixed welding tests.

Fixed welding was performed by fixing the location of the welding wire at the center of the base metal and surrounding the base metal with blocks to prevent molten slag leaking during welding. The following welding conditions were used: a current of $850 \mathrm{~A}$, a voltage of $42 \mathrm{~V}$, and arcing times in the range of $2-400 \mathrm{~s}$. The height from the wire tip to the surface of the base metal was set to $35 \mathrm{~mm}$ up to an arcing time of $60 \mathrm{~s}$ and to $50 \mathrm{~mm}$ after $60 \mathrm{~s}$ to prevent the melting wire from contacting the molten metal. Figure 1 shows a schematic illustration of fixed welding. Figure 2 shows photographs of the test specimens after fixed welding (arcing time of $100 \mathrm{~s}$ ). After welding, the mass of slag and deposited metal was measured and the oxygen content of the weld metal was determined by chemical analysis.

\subsection{Measurement of molten pool temperature}

The temperature of the molten pool of fixed welding was measured using a tungsten-rhenium thermocouple. As shown in Fig. 3, the thermocouple was set at a depth of $20 \mathrm{~mm}$ below the center of the base metal surface.

\section{Results and discussion}

\subsection{Effect of arcing time on weld metal oxygen content}

Figure 4 shows the effect of the flux composition on deoxidization of the weld metal during fixed welding.

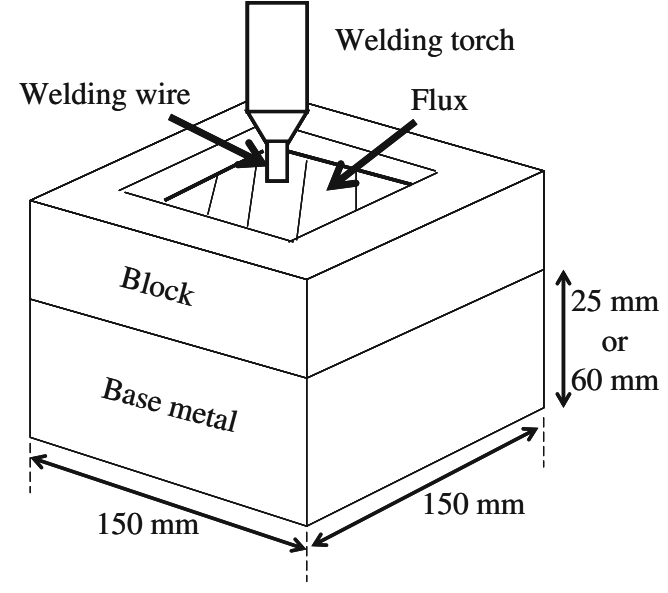

Fig. 1 Schematic illustration of fixed welding

For all three chemical compositions of the flux, the weld metal oxygen content decreases with increasing arcing time in the initial stage of welding. The weld metal oxygen content eventually became constant; this is assumed to be a quasi-equilibrium state. The oxygen content of weld metal in this quasi-equilibrium state, the oxygen content immediately after the commencement of welding, and the reduction rate of the oxygen content of the weld metal all depend on the chemical composition of the flux.

\subsection{Results of molten pool temperature measurements}

The measured molten pool temperature fluctuated (from 1,848 to $1,998 \mathrm{~K}$ ), but its average temperature was $1,923 \mathrm{~K}$.

\subsection{Effect of arcing time on masses of slag and deposited metal}

Figure $5 \mathrm{a}$ shows the measured masses of slag and deposited metal (it was determined by the consumption of welding wire) for fixed welding with flux $\mathrm{A}$ as a function of arcing time; the measured masses of slag and deposited metal increases with increasing arcing time. In addition, the mass fraction of slag to deposited metal decreased with increasing arcing time (Fig. 5b). It
Table 2 Chemical compositions of flux (mass \%)

\begin{tabular}{lllllll}
\hline Mark & $\mathrm{SiO}_{2}$ & $\mathrm{MnO}$ & $\mathrm{CaO}$ & Others & Flux basicity[1] & Viscosity at 1,773 K (Pa s) \\
\hline $\mathrm{A}$ & 40 & 18 & 22 & 20 & 0.93 & 0.122 \\
$\mathrm{~B}$ & 21 & 20 & 20 & 39 & 1.19 & 0.106 \\
$\mathrm{H}$ & 35 & 20 & 20 & 25 & 1.21 & 0.065 \\
$\mathrm{I}$ & 32 & 17 & 17 & 34 & 1.24 & 0.026 \\
$\mathrm{~J}$ & 25 & 20 & 20 & 35 & 1.97 & 0.031 \\
\hline
\end{tabular}


Fig. 2 Photographs of test specimens after fixed welding (arcing time $=100 \mathrm{~s}$ ) a

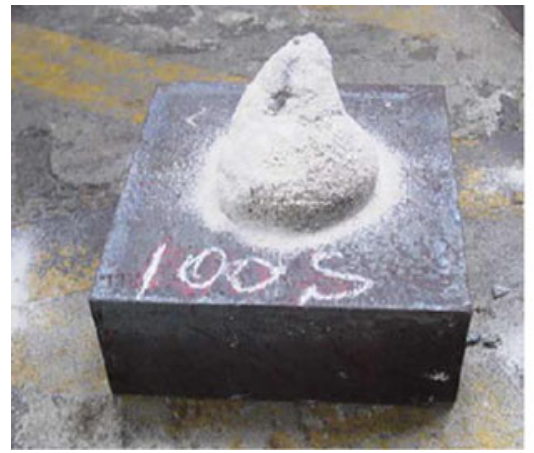

Before slag removal b

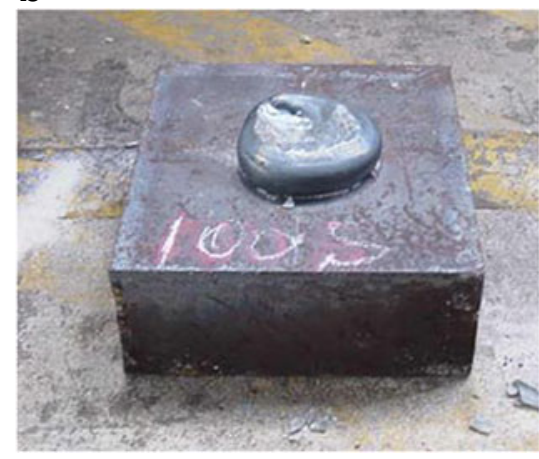

After slag removal became approximately constant at 1.0 when the arcing time exceeded $100 \mathrm{~s}$.

\subsection{Estimate of weld metal oxygen content in quasi-equilibrium state}

Figure 4 shows that the oxygen content of the weld metal decreases with increasing arcing time in the initial stage of welding and that it eventually becomes constant in what is assumed to be a quasi-equilibrium state. This behavior suggests that the deoxidization reaction reaches equilibrium in molten slag and molten metal. In addition, the weld metal oxygen content in the quasi-equilibrium condition depends on the chemical composition of the flux. Therefore, we estimated the oxygen content of the molten metal in the equilibrium condition between the molten slag and molten metal using thermodynamic calculation software (FactSage) and the estimated and experimental oxygen contents were compared. In the thermodynamic calculation, the temperature and mass fraction of the slag to the deposited metal were respectively taken to be $1,923 \mathrm{~K}$ and 1.0 based on experimental results. In addition, the chemical composition of the molten metal used in the

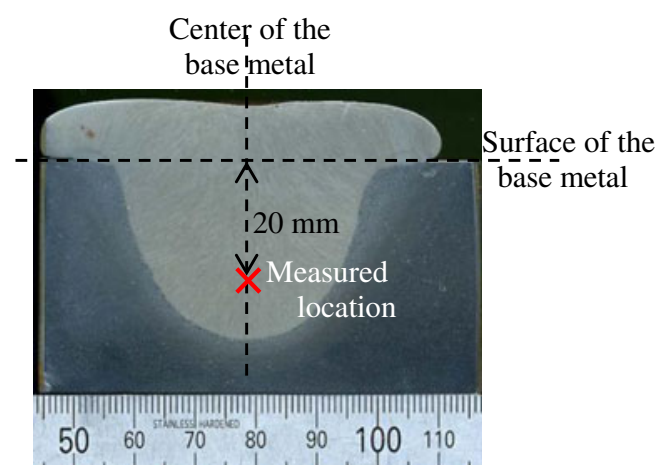

Fig. 3 Measurement location of molten pool temperature equilibrium calculation (see Table 3) was determined from a dilution ratio of the base metal in fixed welding.

Figure 6 shows the relationship between the experimental and estimated oxygen contents. The data point indicated by the arrow indicates the flux for which the oxygen content of the weld metal had not reached the quasi-equilibrium condition in this experiment. If the oxygen content of the weld metal had reached the quasi-equilibrium state, the experimental oxygen content would have been lower. With the exception of the data point indicated by the arrow, the estimated oxygen content approximately corresponds to the experimental oxygen content. This demonstrates that the weld metal oxygen content in the quasi-equilibrium state can be estimated thermodynamically.

\subsection{Modeling of deoxidization of weld metal in fixed welding}

As shown in Fig. 4, the oxygen content of the weld metal decreases with increasing arcing time in the initial stage of welding and it eventually becomes constant in what is assumed to be a quasi-equilibrium state for all

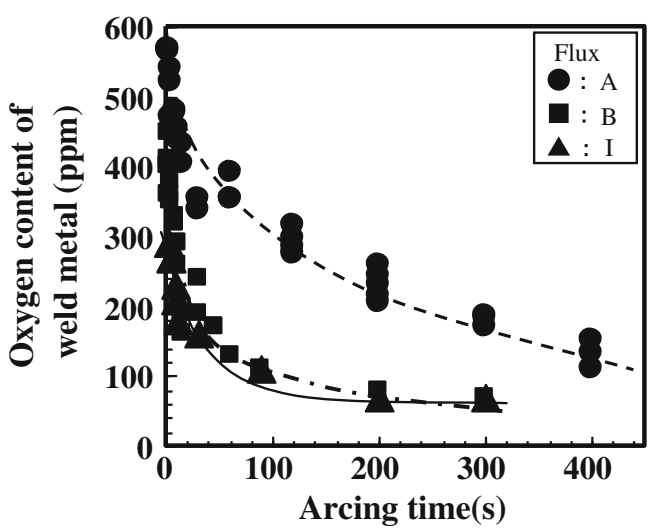

Fig. 4 Effect of flux composition on deoxidization of weld metal during fixed welding 
Fig. 5 a Measured masses of slag and deposited metal for fixed welding with flux $\mathrm{A}$ and $\mathbf{b}$ mass fraction of slag to deposited metal as a function of arcing time

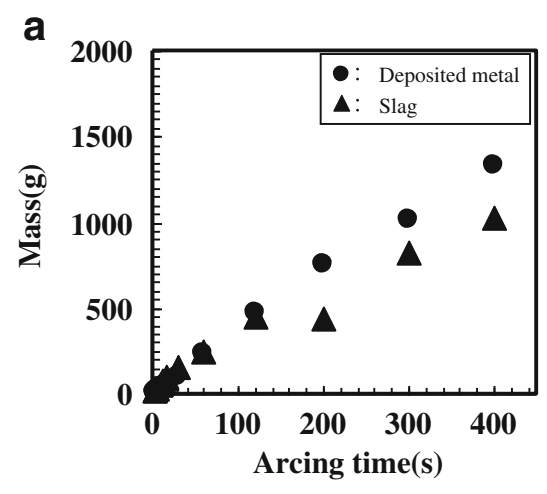

b

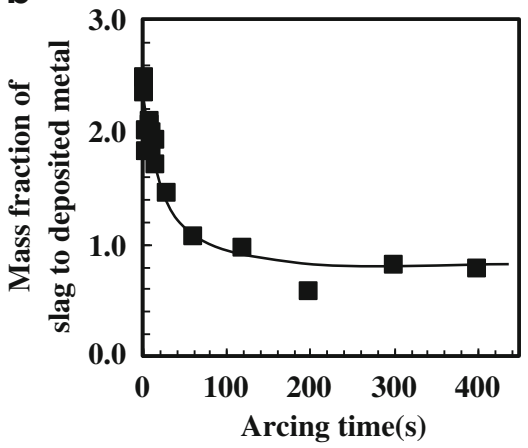

Table 3 Chemical composition of molten metal used in equilibrium calculation (mass $\%)$

\begin{tabular}{llllllllll}
\hline $\mathrm{C}$ & $\mathrm{Si}$ & $\mathrm{Mn}$ & $\mathrm{Cu}$ & $\mathrm{Ni}$ & $\mathrm{Cr}$ & $\mathrm{Mo}$ & $\mathrm{Al}$ & $\mathrm{Ti}$ & $\mathrm{Fe}$ \\
\hline 0.08 & 0.20 & 1.20 & 0.15 & 1.00 & 0.40 & 0.20 & 0.01 & 0.02 & $\mathrm{Bal}$.
\end{tabular}
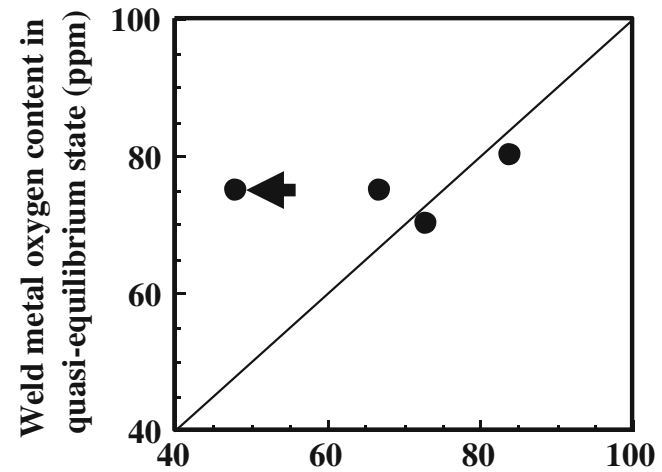

Estimated weld metal oxygen content in equilibrium condition (ppm)

Fig. 6 Relationship between estimated and experimental oxygen contents

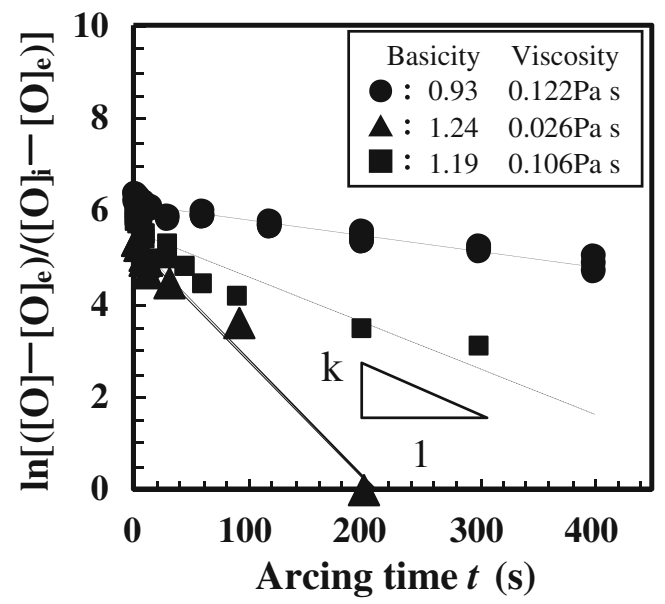

Fig. 7 Relationship between arcing time and $\ln [([\mathrm{O}]-[\mathrm{O}] \mathrm{e}) /([\mathrm{O}] \mathrm{i}-[\mathrm{O}] \mathrm{e})]$

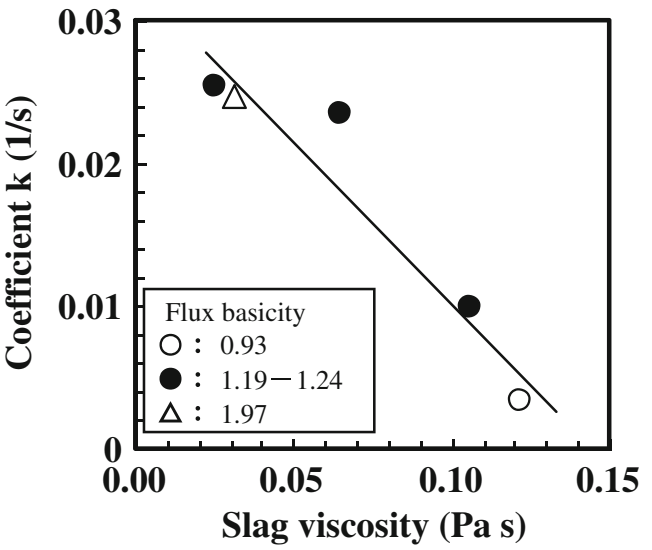

Fig. 8 Relationship between coefficient $k$ and slag viscosity

chemical compositions of the flux. The rate of $\mathrm{Si}$ and $\mathrm{Si}-\mathrm{Mn}$ deoxidization in TIG arc melting has been described by a linear reaction rate equation [5]. In addition, the deoxidization reaction between acidic slag and high-oxygen-content iron has been described by a linear reaction rate equation [6]. These experimental results suggest that it may be possible to describe the deoxidization of a submerged arc weld metal by molten slag under arc welding by a linear reaction rate equation. Therefore, we describe the deoxidization of weld metal during fixed welding by Eq. (1). When the flux for which the weld metal oxygen content has not reached a quasi-equilibrium state in this experiment, $[\mathrm{O}]_{\mathrm{e}}$ is determined by a thermodynamic calculation between the molten slag and molten metal. It is based on the result obtained in the previous section.

$[O]=\exp \left[-k \cdot t+\ln \left([\mathrm{O}]_{\mathrm{i}}-[\mathrm{O}]_{\mathrm{e}}\right)\right]+[\mathrm{O}]_{\mathrm{e}}$

$[\mathrm{O}]_{\mathrm{i}}$ oxygen content immediately after welding starts (in parts per million)

$[\mathrm{O}]_{\mathrm{e}}$ Oxygen content in quasi-equilibrium state (in parts per million)

[O] Oxygen content at arcing time $t$ (in parts per million) $k$ Coefficient

$t$ Arcing time (in seconds) 
Fig. 9 Schematic illustration of effect of slag viscosity on deoxidization

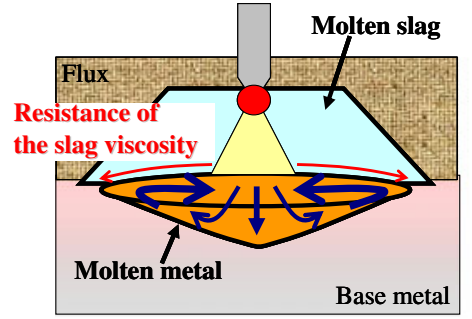

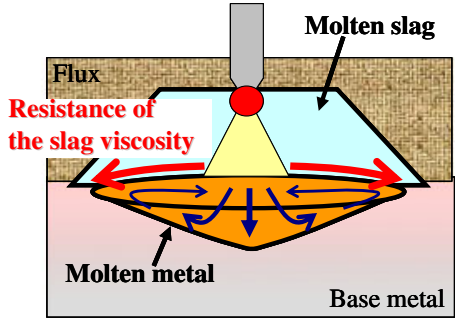

Figure 7 shows the relationship between $\ln \left[\left([\mathrm{O}]-[\mathrm{O}]_{\mathrm{e}}\right) /\right.$ $\left.\left([\mathrm{O}]_{\mathrm{i}}[\mathrm{O}]_{\mathrm{e}}\right)\right]$, which was calculated using the experimental results in Fig. 4 and the arcing time. This relationship is linear. This confirms that deoxidization of submerged arc weld metal can be described by Eq. (1). In addition, it shows that coefficient $k$ depends on the chemical composition of the flux. Figure 8 shows the relationship between the coefficient $k$ and slag viscosity. For all flux basicities, this relationship is linear and coefficient $k$ decreases with increasing viscosity of the molten slag. This tendency was confirmed by the following discussion and Fig. 9 .

We assume that deoxidization of a submerged arc weld metal proceeds by a reaction at the interface between the molten slag and molten metal during stirring. Increasing the slag viscosity will reduce the stirring rate of the molten metal due to the increasing resistance at the interface between the molten slag and molten metal. Therefore, coefficient $k$ (i.e., the deoxidization rate) is expected to decrease with decreasing stirring rate of the molten metal.

These results suggest that it may be possible to predict the oxygen content of submerged arc weld metal by the following procedure (see Fig. 10).

1. Deoxidization of submerged arc weld metal is described by Eq. (1).

2. Oxygen content of weld metal in quasi-equilibrium state $[\mathrm{O}]_{\mathrm{e}}$ is estimated thermodynamically.

3. Coefficient $k$ is estimated from molten slag viscosity.

4. Oxygen content immediately after starting welding $[\mathrm{O}]_{\mathrm{i}}$ is determined by fixed welding.

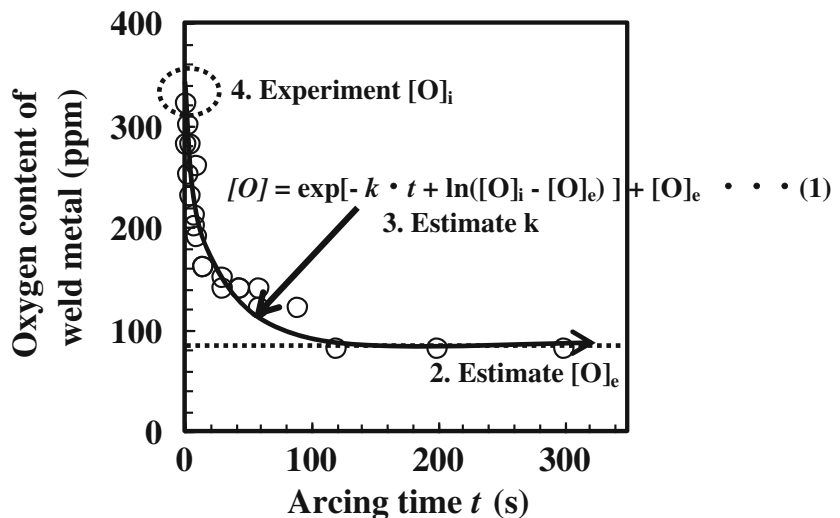

Fig. 10 Procedure for estimating oxygen content of submerged arc weld metal
In the real moving heat source, such as during actual submerged arc welding, it may be considered that the arcing time is equal to the melting time of the weld metal. If the model is applied to real welding, it is necessary to change the arcing time to the melting time of the weld metal.

\section{Conclusions}

This study clarified the deoxidization that occurs during submerged arc welding and proposed a model for determining the weld metal oxygen content. The conclusions are listed below.

(1) The weld metal oxygen content decreased with increasing arcing time, eventually becoming constant in what is assumed to be a quasi-equilibrium state.

(2) The deoxidization process of submerged arc weld metal can be described by a linear reaction rate equation.

(3) The weld metal oxygen content in the quasi-equilibrium state, which depends on the chemical composition of the flux, can be estimated thermodynamically.

(4) For all flux basicities, the coefficient $k$ decreased with increasing molten slag viscosity.

(5) The oxygen content of submerged arc weld metal can be estimated by describing the deoxidization process by a linear reaction rate equation, estimating the weld metal oxygen content in the quasi-equilibrium state $[\mathrm{O}]_{\mathrm{e}}$ and the coefficient $k$, and determining the oxygen content of weld metal immediately after starting welding $[\mathrm{O}]_{\mathrm{i}}$.

Open Access This article is distributed under the terms of the Creative Commons Attribution License which permits any use, distribution, and reproduction in any medium, provided the original author(s) and the source are credited.

\section{References}

1. Nakanishi M (1981) J Jpn Weld Soc 50:5-11, No. 1

2. Eagar TW (1978) Weld J 57:76-80, No. 3

3. Terashima H, Nishiyama N, Tsuboi J (1977) J Jpn Weld Soc 46:165171 , No. 3

4. Terashima H, Tsuboi J (1979) J Jpn Weld Soc 48:626-632, No. 8

5. Tsunetomi E, Katayama H, Fujita H (1969) J Jpn Weld Soc 38:874 880 , No. 8

6. Sano N, Shiomi S, Matsushita Y (1965) Tetsu-to-Hagane 51:170-185, No. 2 